\title{
Single and combined effects of beetroot juice and caffeine supplementation on cycling time trial performance ${ }^{1}$
}

\author{
Stephen C. Lane, John A. Hawley, Ben Desbrow, Andrew M. Jones, James R. Blackwell, Megan L. Ross, \\ Adam J. Zemski, and Louise M. Burke
}

\begin{abstract}
Both caffeine and beetroot juice have ergogenic effects on endurance cycling performance. We investigated whether there is an additive effect of these supplements on the performance of a cycling time trial (TT) simulating the 2012 London Olympic Games course. Twelve male and 12 female competitive cyclists each completed 4 experimental trials in a double-blind Latin square design. Trials were undertaken with a caffeinated gum (CAFF) ( $3 \mathrm{mg} \cdot \mathrm{kg}^{-1}$ body mass (BM), $40 \mathrm{~min}$ prior to the TT), concentrated beetroot juice supplementation (BJ) $\left(8.4 \mathrm{mmol}\right.$ of nitrate $\left(\mathrm{NO}_{3}{ }^{-}\right), 2 \mathrm{~h}$ prior to the TT), caffeine plus beetroot juice (CAFF+BJ), or a control (CONT). Subjects completed the TT (females: $29.35 \mathrm{~km}$; males: $43.83 \mathrm{~km}$ ) on a laboratory cycle ergometer under conditions of best practice nutrition: following a carbohydrate-rich pre-event meal, with the ingestion of a carbohydrateelectrolyte drink and regular oral carbohydrate contact during the TT. Compared with CONT, power output was significantly enhanced after CAFF+BJ and CAFF (3.0\% and 3.9\%, respectively, $p<0.01)$. There was no effect of BJ supplementation when used alone $(-0.4 \%, p=0.6$ compared with CONT) or when combined with caffeine $(-0.9 \%, p=0.4$ compared with CAFF). We conclude that caffeine $\left(3 \mathrm{mg} \cdot \mathrm{kg}^{-1} \mathrm{BM}\right)$ administered in the form of a caffeinated gum increased cycling TT performance lasting $\sim 50-60 \mathrm{~min}$ by $\sim 3 \%-4 \%$ in both males and females. Beetroot juice supplementation was not ergogenic under the conditions of this study.
\end{abstract}

Key words: cycling performance, nitrate, caffeine, ergogenic, time trial, carbohydrate.

Résumé : La caféine et le jus de betterave ont des effets ergogènes sur la performance d'endurance en cyclisme. Dans cette étude, on examine l'effet additif de ces suppléments sur la performance dans une course contre-la-montre («TT») simulant le parcours aux Jeux olympiques de Londres de 2012. Douze femmes et douze hommes, tous des cyclistes de compétition, participent à quatre essais expérimentaux, et ce, selon la méthode du carré latin et à double insu. Les sujets participent aux essais dans les conditions suivantes : gomme renfermant de la caféine ("CAFF »; $3 \mathrm{mg} \cdot \mathrm{kg}^{-1}$ masse corporelle ( $\mathrm{BM}$ ), $40 \mathrm{~min}$ avant la TT), supplément de jus

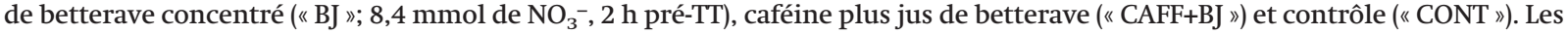
sujets réalisent la TT (femmes : $29,35 \mathrm{~km}$, hommes : 43,83 km) dans un laboratoire sur un cycloergomètre dans un contexte d'une pratique nutritive standard: repas précompétitif riche en sucres, apport d'une boisson contenant des sucres et des électrolytes et consommation régulière de sucreries durant la TT. Comparativement à la condition de contrôle, on observe une augmentation de la puissance générée dans les conditions CAFF+BJ et CAFF (3,0 \% et 3,9\% respectivement, $p<0,01)$. Consommé seul, le jus de betterave n'a pas d'effet $(-0,4 \%, p=0,6$; comparativement à CONT) ou en combinaison avec la caféine $(-0,9 \%, p=0,4$; comparativement à CAFF). En conclusion, la caféine $\left(3 \mathrm{mg} \cdot \mathrm{kg}^{-1} \mathrm{BM}\right)$ administrée sous forme de gomme suscite une amélioration de la performance ( $\sim 50-60 \mathrm{~min})$ de $\sim 3-4 \%$ chez des femmes et des hommes dans un contre-la-montre. [Traduit par la Rédaction]

Mots-clés : performance cycliste, nitrate, caféine, ergogène, contre-la-montre, sucre.

\section{Introduction}

Athletes continually strive to improve training capacity and performance. Not surprisingly, widespread use of a large number of nutritional supplements is commonplace in most sports as athletes search for a "magic bullet" that will elevate their performance to a higher level. Both caffeine (Desbrow et al. 2009; Irwin et al. 2011; Lane et al. 2013a) and nitrate $\left(\mathrm{NO}_{3}{ }^{-}\right.$) (Cermak et al. 2012a; Lansley et al. 2011a; Vanhatalo et al. 2011) have been shown to improve simulated road cycling performance in a variety of protocols. Through mechanisms likely related to the central ner- vous system (CNS) (Costill et al. 1978; Tarnopolsky 2008), caffeine has been shown to improve arousal states (Backhouse et al. 2011) and reduce perceived exertion during steady-state exercise (Backhouse et al. 2011; Doherty and Smith 2005; Lane et al. 2013a), resulting in enhanced performance during sustained high-intensity cycling events (Cox et al. 2002; Lane et al. 2013a; McNaughton et al. 2008). Contemporary protocols for caffeine use are based on evidence that moderate intakes ( $3 \mathrm{mg} \cdot \mathrm{kg}^{-1}$ ) of caffeine are equally as effective as larger doses $\left(6 \mathrm{mg} \cdot \mathrm{kg}^{-1}\right)$ (Desbrow et al. 2012) for eliciting these CNS effects, and that caffeinated gums can also provide a

Received 21 July 2013. Accepted 11 October 2013. Correction after posting 10 March 2014.

S.C. Lane. Exercise and Nutrition Research Group, School of Medical Sciences, RMIT University, Bundoora, VIC 3083, Australia.

J.A. Hawley.* Exercise and Nutrition Research Group, School of Medical Sciences, RMIT University, Bundoora, VIC 3083, Australia; Research Institute for Sport and Exercise Sciences, Liverpool John Moores University, Liverpool, United Kingdom.

B. Desbrow. School of Public Health and Griffith Health Institute, Griffith University, Gold Coast, QLD, Australia.

A.M. Jones and J.R. Blackwell. Sport and Health Sciences, College of Life and Environmental Sciences, University of Exeter, St. Luke's Campus, Exeter, United Kingdom.

M.L. Ross, A.J. Zemski, and L.M. Burke. Sports Nutrition, Australian Institute of Sport, Belconnen, ACT 2626, Australia.

Corresponding author: John A. Hawley (e-mail: john.hawley@acu.edu.au).

*Present address: Exercise and Nutrition Research Group, Australian Catholic University, Fitzroy, VIC 3165, Australia.

${ }^{1}$ This paper is a part of a Special Issue entitled Nutritional Triggers to Adaptation and Performance. 
rapidly absorbed caffeine dose (Kamimori et al. 2002; Ryan et al. 2013). With regard to dietary $\mathrm{NO}_{3}{ }^{-}$supplementation, Jones and colleagues (Bailey et al. 2009, 2010; Lansley et al. 2011a, 2011b; Vanhatalo et al. 2011) reported that ingestion of beetroot juice increases exercise capacity through metabolic mechanisms that improve contraction efficiency in skeletal muscle. We hypothesized that the increased CNS drive and reduced perceived exertion elicited by caffeine supplementation in combination with the previously reported improvements in metabolic efficiency resulting from beetroot juice ingestion would result in higher sustainable power outputs than when each supplement was taken in isolation.

The specific aim of this project was to investigate the independent and combined effects of caffeine and $\mathrm{NO}_{3}{ }^{-}$supplementation on the performance of a cycling task simulating the physical challenges of the London 2012 Olympic Games road cycling time trial (TT). These effects were investigated against the background of a standardized dietary preparation, including strategies that are typical of TT specialists; these included the intake of a small volume of fluid during the event and frequent mouth contact with carbohydrate $(\mathrm{CHO})$ in the form of a sports confectionary, a practice recently confirmed as being beneficial to performance (Carter et al. 2004; Chambers et al. 2009; Lane et al. 2013b; Pottier et al. 2010), even when preceded by a CHO-rich pre-event meal (Lane et al. 2013b). We hypothesized that under optimal nutritional conditions (i) caffeine alone and (ii) $\mathrm{NO}_{3}{ }^{-}$alone supplementation would improve TT performance and (iii) the concurrent use of caffeine and $\mathrm{NO}_{3}{ }^{-}$supplementation would result in an additive performance enhancement compared with when each supplement was used in isolation.

\section{Materials and methods}

\section{Subjects}

Twelve male (mean \pm SD: age $31 \pm 7$ years, body mass $(\mathrm{BM}) 73.4 \pm$ $6.8 \mathrm{~kg}$, height $180.8 \pm 6.1 \mathrm{~cm}$, maximal aerobic power (MAP) $459.4 \pm$ $31.1 \mathrm{~W}$, peak oxygen consumption $\left.\left(\dot{V}_{2 \text { peak }}\right) 71.6 \pm 4.6 \mathrm{~mL} \cdot \mathrm{kg}^{-1} \cdot \mathrm{min}^{-1}\right)$ and 12 female (age $28 \pm 6$ years, BM $62.1 \pm 8.9 \mathrm{~kg}$, height $169.1 \pm$ $8.0 \mathrm{~cm}$, MAP $327.1 \pm 32.3 \mathrm{~W}, \dot{V} \mathrm{O}_{2 \text { peak }} 59.9 \pm 5.1 \mathrm{~mL} \cdot \mathrm{kg}^{-1} \cdot \mathrm{min}^{-1}$ ) competitive cyclists or triathletes volunteered to participate in this study. Ethical clearance was obtained from the Australian Institute of Sport Ethics Committee. Prior to participation, subjects were informed of the nature and risks involved and completed a medical questionnaire before providing written informed consent.

\section{Study overview}

On separate days following familiarization (described subsequently), subjects performed 4 cycling TTs under different experimental conditions: caffeine and beetroot juice supplementation (CAFF+BJ), caffeine and placebo beetroot juice (CAFF), beetroot juice and placebo caffeine (BJ), or a control consisting of a placebo of both caffeine and beetroot juice (CONT). All trials were separated by $\sim 7$ days, and treatments were allocated using a doubleblind Latin square design. Each ride was performed under standardized conditions representing optimal nutritional practice: a CHO-rich pre-event meal, ingestion of small amounts of a CHO-electrolyte drink during the TT, and regular oral $\mathrm{CHO}$ contact in the form of a sports confectionery product. All preliminary testing and experimental trials were performed under standard laboratory environmental conditions.

\section{Incremental cycle test}

In the 2 weeks prior to their first experimental trial, all subjects performed a progressive maximal exercise test to exhaustion on a cycle ergometer (Lode Excalibur Sport, Groningen, The Netherlands). After a 5-min warm-up, the test protocol commenced at 175 and $125 \mathrm{~W}$ for males and females, respectively, and increased by $25 \mathrm{~W}$ every $60 \mathrm{~s}$ until volitional fatigue. MAP was determined to be the power output of the highest stage completed plus the fraction of any uncompleted workload, as described previously (Ross et al. 2011, 2012). Expired gases were collected into a calibrated and customized Douglas bag gas analysis system, which incorporated an automated piston that allowed the concentrations of $\mathrm{O}_{2}$ and $\mathrm{CO}_{2}$ (AEI Technologies, Pittsburg, Pa., USA) and the volume of air displaced to be quantified. The operation and calibration of this equipment have been described previously (Russell et al. 2002). $\dot{V} \mathrm{O}_{2 \text { peak }}$ was calculated as the highest average $\mathrm{O}_{2}$ consumption recorded over $60 \mathrm{~s}$.

\section{Familiarization session}

On the same day as the maximal test, subjects completed a familiarization ride on the same bike and simulated course they would complete in the subsequent experimental trials. In brief, subjects completed the course at their own self-selected intensity with the instruction to familiarize themselves with the course profile, the bike set-up, and the maximal intensity they believed they could sustain for the entire duration of the TT during subsequent rides. During this familiarization, dimensions for the bike set-up were recorded for replication throughout all experimental trials. Subjects were also familiarized with the use of the sports confectionery product (described subsequently) to be used during the experimental trials.

\section{Diet and exercise control}

Subjects consumed a standardized diet for the 24 -h period prior to each experimental trial using the prepackaged standardized diet protocol described previously (Jeacocke and Burke 2010). Dietary goals for this period were $8 \mathrm{~g} \cdot \mathrm{kg}^{-1} \mathrm{BM}$ of CHO; $1.5 \mathrm{~g} \cdot \mathrm{kg}^{-1} \mathrm{BM}$ of protein; $1.5 \mathrm{~g} \cdot \mathrm{kg}^{-1} \mathrm{BM}$ of fat; and $\sim 220 \mathrm{~kJ} \cdot \mathrm{kg}^{-1} \mathrm{BM}$ for the 24 -h period. Subjects were instructed to avoid alcohol for the $24 \mathrm{~h}$ prior to the start of the TT, and to follow their habitual caffeine consumption patterns until $12 \mathrm{~h}$ prior. Caffeine was not withheld for the 24-h period because it has been shown previously that a 3-mg. $\mathrm{kg}^{-1} \mathrm{BM}$ dose of caffeine improves cycling performance irrespective of whether a withdrawal period is imposed on habitual caffeine users (Irwin et al. 2011). To avoid any possible effect on the experimental trials, the provided pretrial standardized diets contained no $\mathrm{NO}_{3}{ }^{-}$-rich products.

Following an initial interview with a sports dietitian (AZ), a food menu was prepared for each subject based on individual BM and food preferences. During the same consultation, subjects reported the ongoing or acute use of any medicine or supplement. In any case in which the subject reported the use of a medicine or supplement that could have influenced performance between trials, the subject was excluded from the study. The subjects' individual menu was prepared using Food Works Professional Edition, version 6.0.2562 (Xyris Software, Brisbane, Australia). Subjects were provided with all foods and drinks in portioncontrolled packages for consumption during the first $22 \mathrm{~h}$ of the dietary control period and were given verbal and written instructions on how to follow the diet. Checklists were used to record each menu item as it was consumed and to note any deviations from the menu. Prior to undertaking each trial, each subject's food checklists were checked and clarified for compliance with the standardization protocols by the sports dietitian. Using the same software, analysis of the actual diet consumed by the subjects was undertaken on completion of the study.

\section{Experimental trials}

Subjects presented to the laboratory on 4 separate occasions, each separated by $\sim 7$ days. On each occasion, subjects presented at the same time of day, voided their bladder prior to having their $\mathrm{BM}$ recorded, and then rested in a supine position for $\sim 10 \mathrm{~min}$. At this time, a Teflon cannula (Terumo, 20-22G, Tokyo, Japan) was inserted into a vein in the antecubital fossa. A resting blood sample $(8 \mathrm{~mL})$ was taken, and the cannula was flushed with saline to 
keep the vein patent for subsequent sampling. Two hours prior to the warm-up for each trial and immediately after the resting blood sample, subjects consumed the remainder of the control diet as a pre-race meal. This meal provided $2 \mathrm{~g} \cdot \mathrm{kg}^{-1} \mathrm{BM}$ of $\mathrm{CHO}$, which was included in the total CHO quota in the 24-h standardized diet. Subjects were instructed to consume their pre-race meal within $20 \mathrm{~min}$, after which time they remained in the laboratory for the duration of that day's experimental trial. Depending on the trial, either the experimental or the placebo beetroot juice concentrate was ingested in 2 separate doses (detailed below). Forty minutes prior to commencement of the TT, subjects completed a standardized warm-up on the same bicycle on which they would perform the TT. The caffeine gum was administered in 2 doses, the first immediately prior to commencement of the warm-up and the second immediately after its completion. Subjects then completed a TT simulating the characteristics of the London Olympic Games cycling TT course specific to the male or female events, under the conditions described subsequently. Mean power output, heart rate, and rating of perceived exertion (RPE) were recorded during each trial. During the first trial, water was provided ad libitum for the time period leading up to commencement of the TT. The volume consumed in this period was recorded and was replicated throughout subsequent trials.

\section{Warm-up}

The warm-up consisted of $30 \mathrm{~min}$ of cycling at varying intensities (13 $\mathrm{min}$ at $25 \%, 5 \mathrm{~min}$ at $60 \%, 2 \mathrm{~min}$ at $70 \%, 3 \mathrm{~min}$ at $25 \%, 5 \mathrm{~min}$ at $60 \%$, and $2 \mathrm{~min}$ at $80 \%$ of MAP). Subjects then rested for $10 \mathrm{~min}$ prior to commencing the TT.

\section{Time trials}

Subjects performed all experimental trials on a Velotron cycle ergometer (Racermate, Seattle, Wash., USA) adjusted to the dimensions of their own bicycles. Males completed a simulated $43.83-\mathrm{km}$ course, whereas females completed a $29.35-\mathrm{km}$ course. The courses were created using global positioning satellite data collected during a prior reconnaissance of the London Olympic TT event. Subjects were instructed to complete the TT as quickly as possible. Financial incentives were offered to encourage maximal effort.

\section{Experimental interventions}

\section{Beetroot juice}

During 2 of the trials, subjects received 2 separate doses of $140 \mathrm{~mL}$ of concentrated $\mathrm{NO}_{3}{ }^{-}$-rich beetroot juice delivering $8.4 \mathrm{mmol}$ of $\mathrm{NO}_{3}{ }^{-}$in each dose (Beet it, James White Drinks Ltd., Ipswich, UK). Each subject ingested the first dose at a specific time $\sim 8$ to $12 \mathrm{~h}$ prior to the commencement of each TT; the dose was provided in each subject's controlled diet, which was consumed the day prior to each experimental trial. The second dose was ingested in the laboratory $130 \mathrm{~min}$ prior to the commencement of the TT. During the 2 placebo trials, a similar-tasting but $\mathrm{NO}_{3}{ }^{-}$-depleted beetroot juice product $\left(\sim 0.006 \mathrm{mmol}\right.$ of $\mathrm{NO}_{3}{ }^{-}$; Beet it, James White Drinks Ltd.) (Lansley et al. 2011b) was administered at time points identical to those for the experimental trials.

\section{Caffeine}

During the 2 caffeine trials, a caffeinated gum (Stay Alert, Amurol Confectioners, Yorkville, Ill., USA) was administered in 2 doses, to deliver a total of $3 \mathrm{mg} \cdot \mathrm{kg}^{-1} \mathrm{BM}$ of caffeine. The gum was administered in a nontransparent package emptied directly into the mouth to avoid possible visual cues about the differences between trials (experimental vs. placebo). The first dose was administered immediately prior to the commencement of the warm-up (40 min prior to the TT) and consisted of a caffeine dose containing $2 \mathrm{mg} \cdot \mathrm{kg}^{-1} \mathrm{BM}$. Subjects were instructed to chew the gum for a total of $10 \mathrm{~min}$ before it was removed and discarded. The remaining dose containing $1 \mathrm{mg} \cdot \mathrm{kg}^{-1} \mathrm{BM}$ was administered with the same instructions at the end of the warm-up (10 min prior to the TT). During the placebo trials, noncaffeinated gum matched for taste and texture (Jila Gum, Ferndale Confectionary Pty Ltd., Australia) was provided under the same conditions as the caffeinated gum.

\section{CHO ingestion}

To ensure that the findings of this study would be relevant when applied in a real-world situation in which athletes follow current nutritional guidelines to maximize performance, a $\mathrm{CHO}$ sports gel (PowerBar Gel, Powerbar Inc., Florham Park, N.J., USA) containing $28 \mathrm{~g}$ CHO was ingested $15 \mathrm{~min}$ prior to the commencement of each TT. Additionally, at the commencement of each TT, subjects were provided with a sports confectionary product (PowerBar Gel Blasts, Powerbar Inc.). Subjects were instructed to place the confectionery item in their mouth and leave it in their cheek cavity until it had dissolved completely, at which time another was provided. The timing and number of confectionery pieces used in the first trial was replicated throughout all subsequent trials. The aim of this procedure was to provide a constant $\mathrm{CHO}$ stimulus in the mouth similar to a $\mathrm{CHO}$ mouth rinse, which has been shown previously to enhance cycling performance (Carter et al. 2004; Chambers et al. 2009; Fares and Kayser 2011; Lane et al. 2013b; Pottier et al. 2010). Subjects also received a CHO-electrolyte sports drink (Gatorade, Gatorade Co., Chicago, Ill., USA) to consume at specific points during each TT. During the first trial, males received 2 bottles, the first at $15 \mathrm{~km}$ and the second at $30 \mathrm{~km}$ during the TT, whereas females received a single bottle at $15 \mathrm{~km}$. These points correspond to portions of the TT in which prior reconnaissance of the course suggested it would be practical for competitors to take a drink. During the first trial, each bottle was preweighed, and subjects were instructed to consume as much fluid as desired within $1 \mathrm{~min}$. Each bottle was then reweighed and the volume of fluid consumed was recorded; this was repeated throughout all subsequent trials.

\section{Blood collection and analysis}

At each sampling time point, a total of $8 \mathrm{~mL}$ of whole blood was collected in a tube containing lithium heparin. Each trial included 4 sampling time points consisting of a resting sample, a sample taken immediately prior to commencement of the warm-up (prior to caffeine ingestion), a third sample taken immediately after the warm-up, and a final sample taken immediately after the TT. Tubes were centrifuged immediately at $4{ }^{\circ} \mathrm{C}$ at $4000 \mathrm{r} \cdot \mathrm{min}^{-1}$ $(3040 \mathrm{~g})$ for $10 \mathrm{~min}$. The resultant plasma was divided into equal aliquots and stored at $-80{ }^{\circ} \mathrm{C}$ for the subsequent analysis of caffeine, $\mathrm{NO}_{3}^{-}$, and nitrite $\left(\mathrm{NO}_{2}^{-}\right)$concentrations.

\section{Plasma caffeine concentration}

The quantitative analysis of plasma caffeine was performed using an automated reverse-phase, high-performance liquid chromatography system. Conditions were adapted from Koch, Tusscher, Koppe, and Guchelaar (Koch et al. 1999) with subtle modifications. The precise method has been described previously (Desbrow et al. 2009).

\section{Plasma $\mathrm{NO}_{3}{ }^{-}$and $\mathrm{NO}_{2}{ }^{-}$concentrations}

Plasma $\mathrm{NO}_{3}{ }^{-}$and $\mathrm{NO}_{2}{ }^{-}$were analyzed by gas phase chemiluminescence analysis. This initially required $\mathrm{NO}_{2}{ }^{-}$and $\mathrm{NO}_{3}{ }^{-}$to be reduced to nitric oxide (NO) gas. For the reduction of $\mathrm{NO}_{2}^{-}$, undiluted plasma was injected into a glass purge vessel containing $5 \mathrm{~mL}$ glacial acetic acid and $1 \mathrm{~mL} \mathrm{NaI}$ solution. For the $\mathrm{NO}_{3}{ }^{-}$reduction, plasma samples were deproteinized in an aqueous solution of zinc sulphate $(10 \% \mathrm{w} / \mathrm{v})$ and $1 \mathrm{~mol} \cdot \mathrm{L}^{-1}$ sodium hydroxide, prior to reduction to $\mathrm{NO}$ in a solution of vanadium (III) chloride in $1 \mathrm{~mol} \cdot \mathrm{L}^{-1}$ hydrochloric acid $(0.8 \% w / v)$. Quantification of NO was enabled by the detection of light emitted during the production of nitrogen dioxide formed upon the reaction of NO with ozone. Luminescence was detected by a thermoelectrically cooled, red-sensitive 
Table 1. Summary of cycling time trial performance and associated measures.

\begin{tabular}{|c|c|c|c|c|c|c|c|}
\hline \multirow[b]{2}{*}{ Intervention } & \multirow[b]{2}{*}{ Time (h:mm:ss.00) } & \multicolumn{2}{|l|}{ Power } & \multirow{2}{*}{$\begin{array}{l}\text { Heart rate } \\
\left(\text { beats } \cdot \mathrm{min}^{-1} \text { ) }\right.\end{array}$} & \multirow{2}{*}{$\begin{array}{l}\text { RPE } \\
(6-20)\end{array}$} & \multicolumn{2}{|c|}{ Body mass $(\mathrm{kg})$} \\
\hline & & $\mathrm{W}$ & $\%$ MAP & & & Pre & $\Delta$ Pre-Post TT \\
\hline \multicolumn{8}{|c|}{ Males $(43.83 \mathrm{~km})$} \\
\hline CONT & 1:03:30.39 $\pm 0: 03: 16.15$ & $303 \pm 41$ & $66 \pm 5.8$ & $167 \pm 11$ & $17 \pm 0.9$ & $73.3 \pm 6.7$ & $-1.1 \pm 0.4$ \\
\hline $\mathrm{CAFF}+\mathrm{BJ}$ & 1:02:38.04 $\pm 0: 03: 31.00^{*}$ & $314 \pm 44^{*}$ & $68 \pm 6.3^{*}$ & $171 \pm 9$ & $17 \pm 0.9$ & $73.6 \pm 6.9$ & $-1.4 \pm 0.3$ \\
\hline CAFF & 1:02:43.86 $\pm 0: 03: 04.87^{*}$ & $313 \pm 38^{*}$ & $68 \pm 4.5^{*}$ & $172 \pm 10$ & $17 \pm 0.8$ & $73.5 \pm 7.0$ & $-1.8 \pm 0.3$ \\
\hline BJ & 1:04:05.03 $\pm 0: 02: 50.09$ & $298 \pm 35$ & $65 \pm 4.8$ & $169 \pm 9$ & $17 \pm 1.0$ & $73.4 \pm 6.9$ & $-1.2 \pm 0.3$ \\
\hline \multicolumn{8}{|c|}{ Females (29.35 km) } \\
\hline CONT & 0:51:40.10 $\pm 0: 02: 31.71$ & $207 \pm 29$ & $63 \pm 6.2$ & $171 \pm 8$ & $17 \pm 1.2$ & $62.2 \pm 8.9$ & $-0.9 \pm 0.4$ \\
\hline $\mathrm{CAFF}+\mathrm{BJ}$ & 0:51:11.88 $\pm 0: 02: 22.13^{*}$ & $212 \pm 27^{*}$ & $65 \pm 5.1^{*}$ & $176 \pm 6$ & $17 \pm 0.8$ & $62.0 \pm 9.1$ & $-0.9 \pm 0.4$ \\
\hline CAFF & 0:50:50.53 $\pm 0: 02: 56.48^{*}$ & $216 \pm 34^{*}$ & $66 \pm 6.4^{*}$ & $174 \pm 9$ & $17 \pm 1.0$ & $62.2 \pm 9.0$ & $-0.7 \pm 0.3$ \\
\hline $\mathrm{BJ}$ & 0:51:41.06 $\pm 0: 02: 39.51$ & $207 \pm 31$ & $63 \pm 6.5$ & $174 \pm 9$ & $17 \pm 0.6$ & $62.4 \pm 9.3$ & $-0.8 \pm 0.5$ \\
\hline \multicolumn{8}{|l|}{ Combined } \\
\hline CONT & - & $250 \pm 57$ & $64 \pm 5.8$ & - & - & - & - \\
\hline $\mathrm{CAFF}+\mathrm{BJ}$ & - & $258 \pm 59$ & $66 \pm 5.6^{*}$ & - & - & - & - \\
\hline CAFF & - & $260 \pm 58$ & $67 \pm 5.4^{*}$ & - & - & - & - \\
\hline $\mathrm{BJ}$ & - & $249 \pm 56$ & $64 \pm 5.6$ & 一 & - & - & - \\
\hline
\end{tabular}

Note: MAP, maximal aerobic power; RPE, rating of perceived exertion; TT, time trial; CONT, placebo of caffeine and beetroot juice; $\mathrm{CAFF}+\mathrm{BJ}$, beetroot juice with caffeine; $\mathrm{CAFF}$, caffeine; $\mathrm{BJ}$, beetroot juice.

*Significantly different from CONT and BJ $(p<0.05)$.

photomultiplier tube housed in a Sievers gas-phase chemiluminescence NO analyzer (Sievers NOA 280i, Analytix Ltd., Durham, UK). The concentrations of $\mathrm{NO}_{2}{ }^{-}$and $\mathrm{NO}_{3}{ }^{-}$were determined by plotting signal area $(\mathrm{mV})$ against a calibration plot of $25 \mathrm{nmol} \cdot \mathrm{L}^{-1}$ to $1 \mu \mathrm{mol} \cdot \mathrm{L}^{-1}$ sodium nitrite and $100 \mathrm{nmol} \cdot \mathrm{L}^{-1}$ to $10 \mu \mathrm{mol} \cdot \mathrm{L}^{-1}$ sodium nitrate, respectively.

\section{Statistical analyses}

Statistical analyses were performed using software package SPSS (version 18). For all blood and physiological measures (combining both male and female results), 1-way analyses of variance (ANOVAs) for repeated measures were used to make comparisons between time points and trials using a Bonferroni adjustment where appropriate. Mean power outputs from the 4 trials were analyzed for males and females separately as well as combined, using the magnitude-based inference approach recommended for studies in sports medicine and exercise (Hopkins et al. 2009). The same inference-based approach was also used to compare time to complete each trial for males and females separately. A spreadsheet (Microsoft Excel), designed to examine post-only crossover trials, was used to determine the clinical significance of each treatment (available at http://sportsci.org/resource/stats/index. html), as based on guidelines outlined by Hopkins (2007). Qualitative inferences are reported as the percentage chance of a positive effect compared with the corresponding trial where a least worthwhile effect on power output of $1 \%$ was used as established previously (Paton and Hopkins 2006). Significance was set at $p<0.05$. All data are presented as means \pm SD unless stated otherwise.

\section{Results}

\section{Body mass}

Among all the trials, there was no difference in BM upon presenting to the laboratory. Similarly, there was no statistical difference among trials in the change in BM before and after each trial (Table 1).

\section{Plasma caffeine}

Figure 1A displays the plasma caffeine concentrations for all trials. At rest, there was a small variation in plasma caffeine concentrations, likely because subjects were instructed to abstain from caffeine only in the $12 \mathrm{~h}$ prior to the trials (Irwin et al. 2011). Within 30 min of ingestion, plasma caffeine concentrations were significantly increased (CAFF+BJ $9.2 \pm 3.2 \mu \mathrm{mol} \cdot \mathrm{L}^{-1}$ and CAFF $10.0 \pm$ $3.80 \mu \mathrm{mol} \cdot \mathrm{L}^{-1}$ ) when compared with resting values and with the noncaffeine trials. Peak caffeine concentrations (CAFF+BJ $16.7 \pm$
$3.1 \mu \mathrm{mol} \cdot \mathrm{L}^{-1}$ and CAFF $17.2 \pm 5.5 \mu \mathrm{mol} \cdot \mathrm{L}^{-1}$ ) were recorded at the final collection point at the end of each TT.

\section{Plasma $\mathrm{NO}_{3}{ }^{-}$and $\mathrm{NO}_{2}{ }^{-}$}

Figure $1 \mathrm{~B}$ shows plasma $\mathrm{NO}_{3}{ }^{-}$concentrations for all trials. The preloading $\mathrm{NO}_{3}{ }^{-}$dose, administered $\sim 6-10 \mathrm{~h}$ prior to the resting blood sample, increased plasma $\mathrm{NO}_{3}{ }^{-}$concentrations in the CAFF+BJ and BJ trials $\left(113.1 \pm 33.3 \mu \mathrm{mol} \cdot \mathrm{L}^{-1}\right.$ and $123.2 \pm 37.6 \mu \mathrm{mol} \cdot \mathrm{L}^{-1}$, respectively; $p<0.01$ ) when compared with the non-beetroot juice trials. Plasma $\mathrm{NO}_{3}{ }^{-}$levels remained significantly elevated in $\mathrm{CAFF}+\mathrm{BJ}$ and $\mathrm{BJ}$ at all time points compared with CAFF and CONT $(p<0.05)$. The second dose of beetroot juice (administered $130 \mathrm{~min}$ prior to the TT) further elevated plasma $\mathrm{NO}_{3}{ }^{-}$concentrations at $90 \mathrm{~min}$ $\left(282.7 \pm 64.8 \mu \mathrm{mol} \cdot \mathrm{L}^{-1}\right.$ and $\left.295.8 \pm 67.0 \mu \mathrm{mol} \cdot \mathrm{L}^{-1}\right)$ and $2 \mathrm{~h}$ after ingestion $\left(310.6 \pm 58.7 \mu \mathrm{mol} \cdot \mathrm{L}^{-1}\right.$ and $\left.333.9 \pm 64.7 \mu \mathrm{mol} \cdot \mathrm{L}^{-1}\right)$ when compared with resting values $(p<0.05)$, with concentrations remaining elevated until after the TT $\left(334.1 \pm 53.3 \mu \mathrm{mol} \cdot \mathrm{L}^{-1}\right.$ and $\left.343.1 \pm 58.4 \mu \mathrm{mol} \cdot \mathrm{L}^{-1}, p<0.05\right)$.

Figure $1 \mathrm{C}$ shows plasma $\mathrm{NO}_{2}{ }^{-}$concentrations for all trials. Concentrations were significantly higher in $\mathrm{CAFF}+\mathrm{BJ}$ and $\mathrm{BJ}$ at all time points compared with CAFF and CONT $(p<0.01)$. The preloading $\mathrm{NO}_{3}{ }^{-}$dose consumed $\sim 6-10 \mathrm{~h}$ prior to the resting blood sample elevated $\mathrm{NO}_{2}{ }^{-}$levels to $176.1 \pm 90.9 \mathrm{nmol} \cdot \mathrm{L}^{-1}$ and $174.3 \pm$ $87.1 \mathrm{nmol} \cdot \mathrm{L}^{-1}(p<0.05)$ for the CAFF+BJ and BJ trials, respectively, compared with the non-beetroot juice trials. The second dose of $\mathrm{NO}_{3}{ }^{-}$-rich beetroot juice did not elevate plasma $\mathrm{NO}_{2}{ }^{-}$concentrations further in the $\mathrm{CAFF}+\mathrm{BJ}$ and $\mathrm{BJ}$ trials.

\section{Power output}

Figure 2 shows the relative mean power output combined for males and females. On average, caffeine improved mean power output when compared with CONT in the CAFF+BJ and CAFF trials by $3.5 \%(p<0.01)$. Beetroot juice supplementation had no effect on mean power output in either CAFF+BJ vs. CAFF or BJ vs. CONT. Using an inference-based statistical approach, caffeine was very likely (99\%) and very likely (97\%) (CAFF+BJ vs. BJ and CAFF vs. CONT, respectively) to have a positive effect on performance outcomes during a cycling TT. $\mathrm{NO}_{3}{ }^{-}$supplementation was most unlikely $(0 \%)$ and very unlikely (1\%) (BJ vs. CONT and CAFF+BJ vs. CAFF, respectively) to have any positive effect on performance. When mean power output was compared for trial order rather than intervention, no significance was detected among any trials (Trials 1 through 4: males $298 \pm 40 \mathrm{~W}, 301 \pm 35 \mathrm{~W}, 306 \pm 40 \mathrm{~W}$, and $305 \pm 37 \mathrm{~W}$, respectively; females $212 \pm 30 \mathrm{~W}, 210 \pm 26 \mathrm{~W}, 212 \pm$ $34 \mathrm{~W}$, and $208 \pm 31 \mathrm{~W}$, respectively; $p=1.0$ ), indicating that the 
Fig. 1. Plasma concentrations. (A) Caffeine. (B) $\mathrm{NO}_{3}{ }^{-}$. (C) $\mathrm{NO}_{2}{ }^{-}$. Times are relative to ingestion. "Rest" in $\mathrm{B}$ and $\mathrm{C}$ includes a "preload" $\mathrm{NO}_{3}{ }^{-}$dose $\sim 6-10 \mathrm{~h}$ prior to the TT. Data are presented as means \pm SD. BJ+CAFF, beetroot juice with caffeine; CAFF, caffeine; BJ, beetroot juice; CONT, placebo of caffeine and beetroot juice. TT, time trial; $\mathrm{NO}_{3}{ }^{-}$, nitrate; $\mathrm{NO}_{2}{ }^{-}$, nitrite. *, Different from CONT and $\mathrm{BJ}(p<0.01)$; $\dagger$, different from CONT and CAFF $(p<0.01)$; a, different from REST and $0 \mathrm{~min}(p<0.01)$; b, different from REST, $0 \mathrm{~min}$, and $30 \mathrm{~min}$ $(p<0.05)$; c, different from REST.

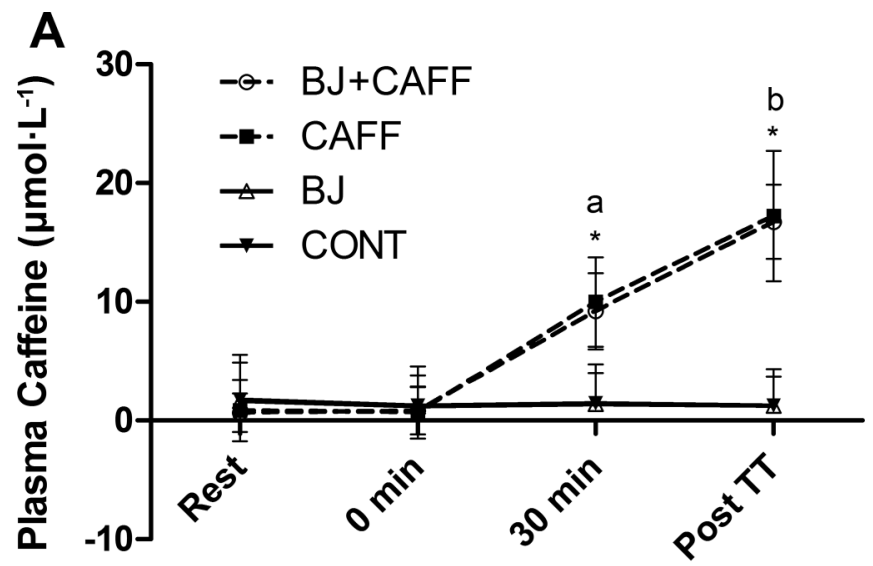

B

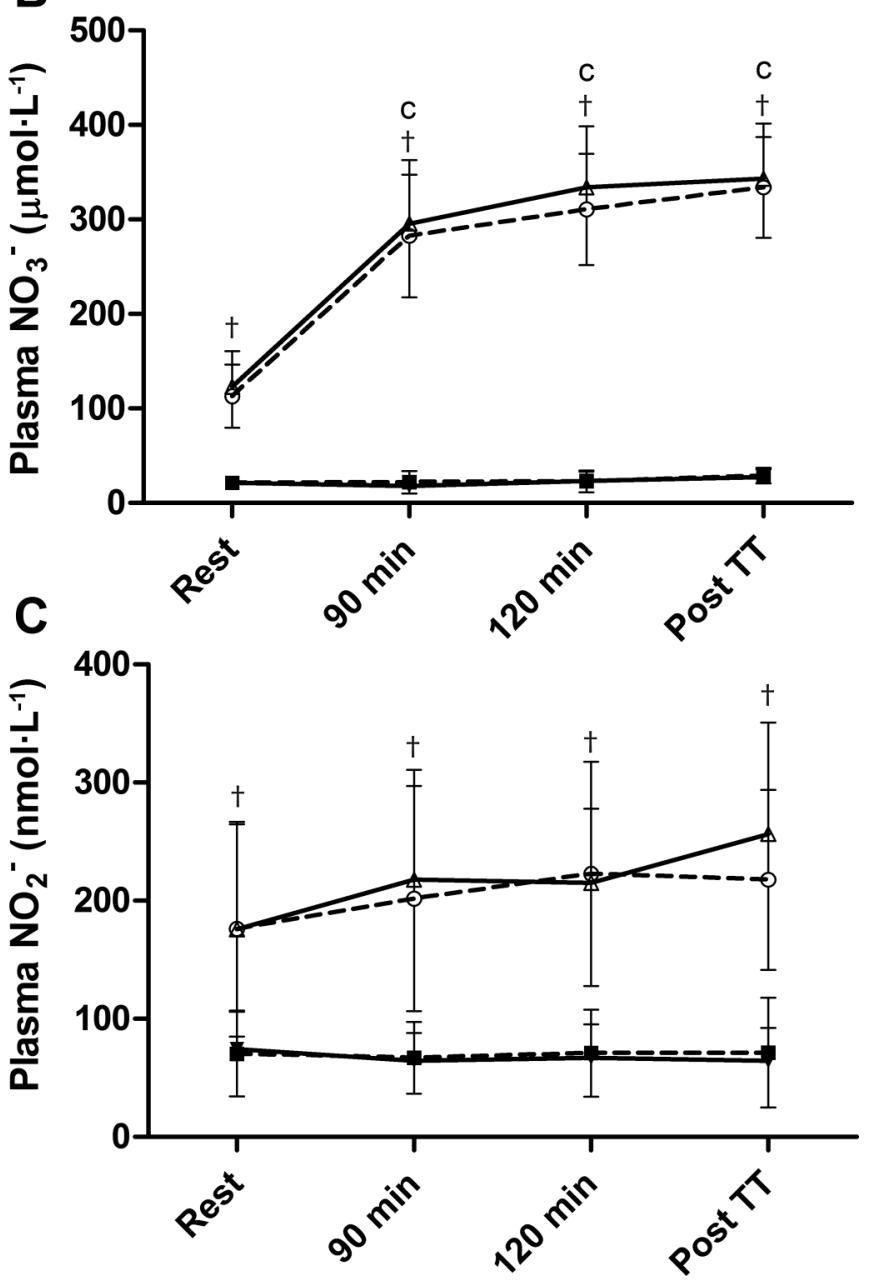

Fig. 2. Mean power output combined for males and females. Data are presented as means $\pm \mathrm{SD}$. $\mathrm{CAFF}+\mathrm{BJ}$, beetroot juice with caffeine; CAFF, caffeine; BJ, beetroot juice; CONT, placebo of caffeine and beetroot juice. *, Different from CONT and BJ $(p<0.01)$.

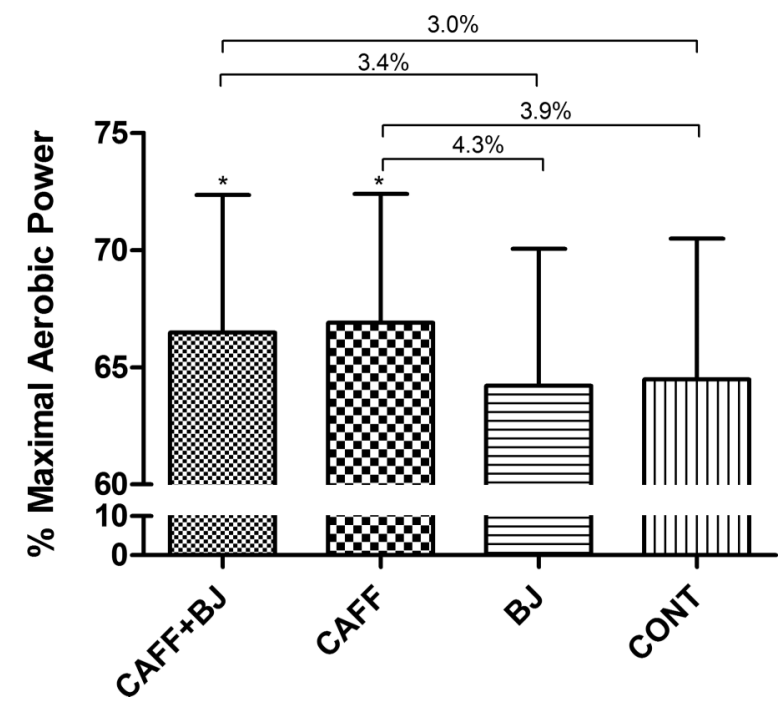

Latin square design was successful in eliminating any possible trial order effect.

\section{TT completion time}

Times to complete the respective distances for males and females are presented in Table 1 . For males, when compared with CONT, the time to complete the $43.83-\mathrm{km}$ distance was reduced to a similar extent of $1.3 \%(p<0.05)$ for both the CAFF+BJ and CAFF trials. For females, the time to complete the $29.35-\mathrm{km}$ distance was reduced by $0.9 \%$ and $1.6 \%(p<0.05)$ for the CAFF+BJ and CAFF trials, respectively, when compared with CONT. Beetroot juice supplementation had no significant positive or negative effect on time to complete the trials for either males or females in either $\mathrm{CAFF}+\mathrm{BJ}$ vs. CAFF or BJ vs. CONT. Using an inference-based statistical approach, caffeine would possibly (65\%) and likely (89\%) for males and possibly (42\%) and likely (88\%) for females (CAFF+BJ vs. $\mathrm{BJ}$ and CAFF vs. CONT, respectively) produce a positive effect on performance outcomes during a cycling TT. $\mathrm{NO}_{3}{ }^{-}$supplementation was unlikely (7\%) and very unlikely $(1 \%)$ for males (CAFF+BJ vs. CAFF and BJ vs. CONT, respectively) and very unlikely (0\%) under both conditions for females to have any positive effect on performance (Table 2).

\section{Heart rate and RPE}

Table 1 shows mean heart rate and RPE for each trial for males and females. There were no differences in mean heart rate or RPE among any trials.

\section{Discussion}

To the best of our knowledge, this is the first study to determine the single and combined effects of caffeine and $\mathrm{NO}_{3}{ }^{-}$supplementation on the performance of cycling protocols that simulated real TT courses and was undertaken with the support of nutritional practices considered optimal for elite TT performance. Because each of these ergogenic aids is purported to elicit its performanceenhancing effect via different mechanisms (i.e., central vs. peripheral), we hypothesized that the combination of the 2 interventions would increase mean power output to a greater extent than when each intervention was administered in isolation. Our results indicate that caffeine supplementation provided a worthwhile enhancement of TT performance to both male and female cyclists, 
Table 2. Power improvement for respective trials.

\begin{tabular}{llc}
\hline & $\% \Delta( \pm 90 \% \mathrm{CL})$ & $p$ \\
\hline CAFF vs. CONT & $4.0 \pm 1.7$ & $<0.001$ \\
CAFF+BJ vs. CONT & $3.1 \pm 1.9$ & 0.01 \\
BJ vs. CONT & $-0 \pm 1.3$ & 0.6 \\
CAFF vs. BJ & $4.2 \pm 1.8$ & $<0.001$ \\
CAFF+BJ vs. BJ & $3.4 \pm 1.6$ & $<0.001$ \\
CAFF+BJ vs. CAFF & $-1 \pm 1.7$ & 0.4 \\
\hline
\end{tabular}

Note: CL, confidence limit; CAFF, caffeine; CONT, placebo of caffeine and beetroot juice; $\mathrm{CAFF}+\mathrm{BJ}$, beetroot juice with caffeine; BJ, beetroot juice.

but that beetroot juice did not provide a detectable benefit under these conditions.

In the current study, pre-event supplementation with caffeine (3 mg. $\mathrm{kg}^{-1} \mathrm{BM}$ ) increased mean power output in cycling TTs lasting $\sim 50 \mathrm{~min}$ (competitive female cyclists) and $\sim 60 \mathrm{~min}$ (competitive male cyclists) to an extent $(\sim 3 \%-4 \%)$ similar to those reported previously using similar caffeine doses (Cox et al. 2002; Irwin et al. 2011; Jenkins et al. 2008; Lane et al. 2013a). In particular, these results are in agreement with the findings of Ryan et al. (2013), who reported that caffeine administered in the form of a gum prior to a cycling TT induced an elevation of circulating caffeine concentrations within $30 \mathrm{~min}$ of intake and resulted in significantly improved performance. We observed that the benefits of ingesting caffeine $40 \mathrm{~min}$ prior to TTs simulating the specific courses undertaken at the 2012 London Olympic Games were similar for males and females, although the courses they rode were slightly different in length and duration. Although these results were derived specifically for the preparation of cyclists for the 2012 Olympic Games, they can be generalized to other events of a similar nature.

It is worth noting that in our study, caffeine ingestion improved performance under the standardized conditions of dietary preparation that are both recommended and typical of the practices of cycling TT specialists. These practices included a CHO-rich preevent meal (Lane et al. 2013b), consumption of a small fluid intake during the event according to the practical opportunities to drink (Garth and Burke 2013), and frequent mouth contact with $\mathrm{CHO}$ (Lane et al. 2013b). Many studies often neglect to recognize that the real-world application of ergogenic interventions may be influenced by optimal race day strategies. Indeed, a meta-analysis has shown that the benefits of caffeine ingestion on endurance performance are reduced when it is taken in combination with $\mathrm{CHO}$ (Conger et al. 2011). However, under the conditions of our study, caffeine ingestion still improved performance to the same degree as reported previously (Cox et al. 2002; Irwin et al. 2011; Jenkins et al. 2008; Lane et al. 2013a; Ryan et al. 2013) when guidelines for optimal CHO ingestion for this specific type of event (Burke et al. 2011) were followed. Finally, our findings are also in agreement with Irwin et al. (2011), who reported a similar degree of improvement in cycling performance when a comparable $\sim 12$-h withdrawal from caffeine was enforced in habitual caffeine users. This observation suggests that longer withdrawal periods (24-48 h), as recommended previously (Burke 2008), may not be necessary.

In contrast, we found no effect of beetroot juice ingestion on a cycling TT lasting $\sim 50-60$ min despite elevated plasma $\mathrm{NO}_{3}{ }^{-}$ $\mathrm{NO}_{2}{ }^{-}$concentrations. Indeed, the conditions under which supplementation with $\mathrm{NO}_{3}{ }^{-}$and beetroot juice ingestion enhances exercise capacity or performance remain somewhat unclear. Elements that could be of importance include the timing and dose of the $\mathrm{NO}_{3}{ }^{-}$, the intensity and duration of the exercise protocol, and the training history or calibre of the athlete. Recently, the effect of beetroot juice on exercise capacity has been shown to be dose dependent, with maximal benefits being seen with the acute ingestion of 2 bottles of beetroot juice concentrate (acute dose of $8.4 \mathrm{mmol} \mathrm{NO}_{3}{ }^{-}$) (Wylie et al. 2013). Because the cyclists in our study ingested the same amount of the same product, both acutely ( $\sim 2 \mathrm{~h}$ before exercise) and as an additional preload (6-10 $\mathrm{h}$ before the trial), we are confident that our failure to detect benefits from $\mathrm{NO}_{3}{ }^{-}$supplementation cannot be explained by a suboptimal dosing protocol.

Our $\mathrm{NO}_{3}{ }^{-}$supplementation protocol substantially elevated plasma $\mathrm{NO}_{2}^{-}$concentrations, although the peak values in our study were lower ( $\left.225 \mathrm{vs} .470-687 \mathrm{nmol} \cdot \mathrm{L}^{-1}\right)$ than those reported by studies employing a similar acute dosing protocol in subjects with a range of training histories (Cermak et al. 2012b; Lansley et al. 2011a; Muggeridge et al. 2013; Wilkerson et al. 2012; Wylie et al. 2013). Although it is only speculation, it is possible that the pre-race meal, consumed shortly before the ingestion of the second beetroot juice dose, may have affected the conversion of $\mathrm{NO}_{3}{ }^{-}$ to $\mathrm{NO}_{2}{ }^{-}$. However, despite this observed difference, Cermak et al. $(2012 b)$ and Wilkerson et al. (2012) reported significantly higher peak plasma $\mathrm{NO}_{2}{ }^{-}$concentrations (532 and $472 \mathrm{nmol} \cdot \mathrm{L}^{-1}$, respectively) compared with the current study, but also failed to detect a performance benefit in well-trained cyclists. Because of the range of plasma $\mathrm{NO}_{2}{ }^{-}$concentrations, varied training histories, and different performance tasks employed, it is difficult to determine whether these observations play a role in the effectiveness of $\mathrm{NO}_{3}{ }^{-}$ supplementation.

The mechanism underpinning the observed benefits of $\mathrm{NO}_{3}{ }^{-}$ supplementation on exercise capacity is believed to be a reduction in the oxygen cost of exercise, as a consequence of a reduced energy cost of contraction or enhanced mitochondrial efficiency (Jones et al. 2012). Whether this translates into an enhancement of performance across a range of exercise intensities has not been studied systematically. However, it is worth noting that the performance of shorter cycling tasks ( $\sim 5-30 \mathrm{~min}$ in duration) has been enhanced following $\mathrm{NO}_{3}{ }^{-}$supplementation. For example, in a study by Lansley et al. (2011a), subjects who sustained intensities equivalent to $\sim 98 \%$ and $95 \%$ of maximal oxygen consumption $\left(\dot{V}_{2 \max }\right)$ during 4-km and 16.1-km TTs, respectively, recorded an improvement in performance after beetroot juice supplementation. However, a 50-mile cycling TT lasting $\sim 135 \mathrm{~min}$ and eliciting a sustained exercise intensity equivalent to $\sim 74 \%$ of $\dot{V} \mathrm{O}_{2 \max }$ did not show a performance benefit following $\mathrm{NO}_{3}{ }^{-}$supplementation, despite subjects showing an improvement in power output per oxygen volume (W/L·min ${ }^{-1}$ ) (Wilkerson et al. 2012). Cermak et al. $(2012 b)$ also reported no enhancement of 1-h cycling TT performance in a cohort of well-trained cyclists using an acute $\mathrm{NO}_{3}-$ dose and timing strategy similar to that employed in the current study.

We did not measure oxygen consumption during the TT in the current study; however, Coyle et al. (1991) reported that welltrained cyclists completed a 1-h TT at $\sim 87 \% \dot{V O}_{2 \text { max }}$, suggesting that our comparable subjects worked at a lower percentage of their aerobic capacity than did those observed in shorterduration tasks as employed in the study by Lansley et al. (2011a). Possible explanations for this observation include the effects of exercise intensity on muscle oxygenation and motor unit recruitment. Higher exercise intensities are likely to result in a greater degree of skeletal muscle hypoxia, which would be expected to facilitate NO production through the reduction of $\mathrm{NO}_{2}{ }^{-}$(Maher et al. 2008). In addition, higher exercise intensities would be expected to mandate a greater recruitment of type II muscle fibres. There is evidence that the effects of $\mathrm{NO}_{3}{ }^{-}$supplementation on blood flow (Ferguson et al. 2013), muscle force, and calcium handling (Hernandez et al. 2012) may be more pronounced in type II fibres. These observations merit further investigation because it appears that the effectiveness of $\mathrm{NO}_{3}{ }^{-}$ supplementation may be influenced by the intensity of the performance task.

The failure to find a benefit of $\mathrm{NO}_{3}{ }^{-}$supplementation in highly trained athletes may be because of a factor that has not yet been identified. For example, studies in which pre-event ingestion of beetroot juice has been unable to produce a detectable improve- 
ment in performance have involved subelite or well-trained cohorts (Cermak et al. 2012b; Christensen et al. 2013; Muggeridge et al. 2013; Wilkerson et al. 2012). A recent meta-analysis of studies of beetroot juice and $\mathrm{NO}_{3}{ }^{-}$supplementation and endurance performance published before August 2012 found that the effects were observed more readily in inactive to recreationally active individuals (Hoon et al. 2013). Clearly, this intriguing aspect warrants further study, with candidate explanations including the optimization of arginine-mediated pathways of NO production in highly trained individuals, or differences in muscle fibre type (Christensen et al. 2013).

It is noteworthy that Cermak et al. (2012a) reported a significant improvement in 10-km cycle TT performance following 6 days of beetroot juice supplementation but no effect on 1-h TT performance after acute beetroot juice intake (Cermak et al. 2012b). Although this finding may be related to differences in exercise duration and intensity, as discussed earlier, it is also possible that longer periods of beetroot juice supplementation are necessary for performance changes to be realized in highly trained subjects. For example, changes in proteins related to mitochondrial efficiency (Larsen et al. 2011) and muscle calcium handling (Hernandez et al. 2012) that have been reported following $\mathrm{NO}_{3}{ }^{-}$supplementation are likely to take several days (rather than hours) to become manifest.

Previous studies have suggested that there may be "responders" and "nonresponders" to dietary $\mathrm{NO}_{3}{ }^{-}$supplementation (Christensen et al. 2013; Wilkerson et al. 2012; Wylie et al. 2013), and this observation appears to be consistent in a highly trained cohort (Christensen et al. 2013; Wilkerson et al. 2012). In the current study, only 2 male individuals recorded better performances in both BJ vs. CONT and CAFF+BJ vs. CAFF, suggesting that they were possible responders. In comparison, Christensen and colleagues (2013) noted that 2 of the 10 highly trained cyclists in their study (mean aerobic capacity of $72.1 \mathrm{~mL} \cdot \mathrm{kg}^{-1} \cdot \mathrm{min}^{-1} \mathrm{vs} .71 .6 \mathrm{~mL} \cdot \mathrm{kg}^{-1} \cdot \mathrm{min}^{-1}$ in the male cyclists in the current study) appeared to benefit from a chronic beetroot juice intake protocol, deriving a $\sim 3 \%$ improvement in performance of an $\sim 18$-min TT compared with a control condition. Factors to explain individual responsiveness to such supplementation remain elusive at present.

In conclusion, we have provided evidence that a caffeine gum containing $3 \mathrm{mg} \cdot \mathrm{kg}^{-1} \mathrm{BM}$ ingested in the $40 \mathrm{~min}$ prior to a cycling TT lasting $\sim 45-60 \mathrm{~min}$ increases cycling power output in both males and females. However, despite increasing circulating $\mathrm{NO}_{3}{ }^{-}$ and $\mathrm{NO}_{2}^{-}$concentrations, beetroot juice supplementation ingested $\sim 8-12 \mathrm{~h}$ prior to the TT as well as an acute dose ingested $\sim 2 \mathrm{~h}$ prior to the TT did not enhance cycling performance either in isolation or in combination with caffeine ingestion. Based on previous evidence that $\mathrm{NO}_{3}{ }^{-}$supplementation can improve performance in a variety of high-intensity endurance tasks, we cannot rule out the possibility that an additive effect may still be possible with different protocols or in specific individuals (responders). Further research is required to determine if $\mathrm{NO}_{3}{ }^{-}$supplementation, when coingested with caffeine, can further enhance performance under shorter, more intense tasks in which the benefit of $\mathrm{NO}_{3}{ }^{-}$supplementation is more pronounced.

\section{Acknowledgements}

We acknowledge the hard work and commitment of the athletes who gave their time to participate in this research project. We also thank Greg Shaw for his assistance in conducting the study and developing the placebo gum protocol, as well as all the people who assisted in recording data during the trials.

This project was funded by a research grant from the Australian Institute of Sport (AIS) Sports Supplement Program and AIS Sports Nutrition.

\section{References}

Backhouse, S.H., Biddle, S.J., Bishop, N.C., and Williams, C. 2011. Caffeine ingestion, affect and perceived exertion during prolonged cycling. Appetite, 57(1): 247-252. doi:10.1016/j.appet.2011.05.304. PMID:21605608.

Bailey, S.J., Winyard, P., Vanhatalo, A., Blackwell, J.R., Dimenna, F.J., Wilkerson, D.P., et al. 2009. Dietary nitrate supplementation reduces the O2 cost of low-intensity exercise and enhances tolerance to high-intensity exercise in humans. J. Appl. Physiol. 107(4): 1144-1155. doi:10.1152/japplphysiol. 00722.2009. PMID:19661447.

Bailey, S.J., Fulford, J., Vanhatalo, A., Winyard, P.G., Blackwell, J.R., DiMenna, F.J., et al. 2010. Dietary nitrate supplementation enhances muscle contractile efficiency during knee-extensor exercise in humans. J. Appl. Physiol. 109(1): 135-148. doi:10.1152/japplphysiol.00046.2010. PMID:20466802.

Burke, L.M. 2008. Caffeine and sports performance. Appl. Physiol. Nutr. Metab. 33(6): 1319-1334. doi:10.1139/H08-130. PMID:19088794.

Burke, L.M., Hawley, J.A., Wong, S.H., and Jeukendrup, A.E. 2011. Carbohydrates for training and competition. J. Sports Sci. 29(Suppl. 1): S17-S27. doi:10.1080/ 02640414.2011.585473. PMID:21660838.

Carter, J.M., Jeukendrup, A.E., and Jones, D.A. 2004. The effect of carbohydrate mouth rinse on 1-h cycle time trial performance. Med. Sci. Sports Exerc. 36(12): 2107-2111. doi:10.1249/01.MSS.0000147585.65709.6F. PMID:15570147.

Cermak, N.M., Gibala, M.J., and van Loon, L.J. 2012a. Nitrate supplementation's improvement of $10-\mathrm{km}$ time-trial performance in trained cyclists. Int. J. Sport Nutr. Exerc. Metab. 22(1): 64-71. PMID:22248502.

Cermak, N.M., Res, P., Stinkens, R., Lundberg, J.O., Gibala, M.J., and van Loon, L.J. $2012 \mathrm{~b}$. No improvement in endurance performance after a single dose of beetroot juice. Int. J. Sport Nutr. Exerc. Metab. 22(6): 470-478. PMID: 23212319.

Chambers, E.S., Bridge, M.W., and Jones, D.A. 2009. Carbohydrate sensing in the human mouth: effects on exercise performance and brain activity. J. Physiol. 587(8): 1779-1794. doi:10.1113/jphysiol.2008.164285. PMID:19237430.

Christensen, P.M., Nyberg, M., and Bangsbo, J. 2013. Influence of nitrate supplementation on $\mathrm{VO}_{2}$ kinetics and endurance of elite cyclists. Scand. J. Med. Sci. Sports, 23(1): e21-e31. doi:10.1111/sms.12005. PMID:23020760.

Conger, S.A., Warren, G.L., Hardy, M.A., and Millard-Stafford, M.L. 2011. Does caffeine added to carbohydrate provide additional ergogenic benefit for endurance? Int. J. Sport Nutr. Exerc. Metab. 21(1): 71-84. PMID:21411838.

Costill, D.L., Dalsky, G.P., and Fink, W.J. 1978. Effects of caffeine ingestion on metabolism and exercise performance. Med. Sci. Sports, 10(3): 155-158. PMID: 723503.

Cox, G.R., Desbrow, B., Montgomery, P.G., Anderson, M.E., Bruce, C.R., Macrides, T.A., et al. 2002. Effect of different protocols of caffeine intake on metabolism and endurance performance. J. Appl. Physiol. 93(3): 990-999. PMID:12183495.

Coyle, E.F., Feltner, M.E., Kautz, S.A., Hamilton, M.T., Montain, S.J., Baylor, A.M., et al. 1991. Physiological and biomechanical factors associated with elite endurance cycling performance. Med. Sci. Sports Exerc. 23(1): 93-107. doi:10. 1249/00005768-199101000-00015. PMID:1997818.

Desbrow, B., Barrett, C.M., Minahan, C.L., Grant, G.D., and Leveritt, M.D. 2009. Caffeine, cycling performance, and exogenous CHO oxidation: a doseresponse study. Med. Sci. Sports Exerc. 41(9): 1744-1751. doi:10.1249/MSS. 0b013e3181a16cf7. PMID:19657295.

Desbrow, B., Biddulph, C., Devlin, B., Grant, G.D., Anoopkumar-Dukie, S., and Leveritt, M.D. 2012. The effects of different doses of caffeine on endurance cycling time trial performance. J. Sports Sci. 30(2): 115-120. doi:10.1080/ 02640414.2011.632431. PMID:22142020.

Doherty, M., and Smith, P.M. 2005. Effects of caffeine ingestion on rating of perceived exertion during and after exercise: a meta-analysis. Scand. J. Med. Sci. Sports, 15(2): 69-78. doi:10.1111/j.1600-0838.2005.00445.x. PMID:15773860.

Fares, E.J., and Kayser, B. 2011. Carbohydrate mouth rinse effects on exercise capacity in pre- and postprandial States. J. Nutr. Metab. 385962. doi:10.1155/ 2011/385962. PMID:22013515.

Ferguson, S.K., Hirai, D.M., Copp, S.W., Holdsworth, C.T., Allen, J.D., Jones, A.M., et al. 2013. Impact of dietary nitrate supplementation via beetroot juice on exercising muscle vascular control in rats. J. Physiol. 591(2): 547-557. doi:10. 1113/jphysiol.2012.243121. PMID:23070702.

Garth, A.K., and Burke, L.M. 2013. What do athletes drink during competitive sporting activities? Sports Med. 43(7): 539-564. doi:10.1007/s40279-0130028-y. PMID:23529286.

Hernandez, A., Schiffer, T.A., Ivarsson, N., Cheng, A.J., Bruton, J.D., Lundberg, J.O., et al. 2012. Dietary nitrate increases tetanic [Ca2+]i and contractile force in mouse fast-twitch muscle. J. Physiol. 590(15): 3575-3583. doi:10.1113/jphysiol.2012.232777. PMID:22687611.

Hoon, M.W., Johnson, N.A., Chapman, P.G., and Burke, L.B. 2013. The effect of nitrate supplementation on exercise performance in healthy individuals: a systematic review and meta-analysis. Int. J. Sport Nutr. Exerc. Metab. 23(5): 522-532. PMID:23580439.

Hopkins, W.G. 2007. A spreadsheet for deriving a confidence interval, mechanistic inference and clinical inference from a P value. Sportscience, 11: 16-20.

Hopkins, W.G., Marshall, S.W., Batterham, A.M., and Hanin, J. 2009. Progressive statistics for studies in sports medicine and exercise science. Med. Sci. Sports Exerc. 41(1): 3-13. doi:10.1249/MSS.0b013e31818cb278. PMID:19092709.

Irwin, C., Desbrow, B., Ellis, A., O’Keeffe, B., Grant, G., and Leveritt, M. 2011. 
Caffeine withdrawal and high-intensity endurance cycling performance. J. Sports Sci. 29(5): 509-515. doi:10.1080/02640414.2010.541480. PMID:21279864.

Jeacocke, N.A., and Burke, L.M. 2010. Methods to standardize dietary intake before performance testing. Int. J. Sport Nutr. Exerc. Metab. 20(2): 87-103. PMID:20479482.

Jenkins, N.T., Trilk, J.L., Singhal, A., O’Connor, P.J., and Cureton, K.J. 2008. Ergogenic effects of low doses of caffeine on cycling performance. Int. J. Sport Nutr. Exerc. Metab. 18(3): 328-342. PMID:18562777.

Jones, A.M., Bailey, S.J., and Vanhatalo, A. 2012. Dietary nitrate and $\mathrm{O}(2)$ consumption during exercise. Med. Sport Sci. 59: 29-35. doi:10.1159/000342062. PMID:23075552.

Kamimori, G.H., Karyekar, C.S., Otterstetter, R., Cox, D.S., Balkin, T.J., Belenky, G.L., et al. 2002. The rate of absorption and relative bioavailability of caffeine administered in chewing gum versus capsules to normal healthy volunteers. Int. J. Pharm. 234(1-2): 159-167. doi:10.1016/S0378-5173(01)00958-9. PMID:11839447.

Koch, J.P., ten Tusscher, G.W., Koppe, J.G., and Guchelaar, H.J. 1999. Validation of a high-performance liquid chromatography assay for quantification of caffeine and paraxanthine in human serum in the context of CYP1A2 phenotyping. Biomed. Chromatogr. 13(4): 309-314. doi:10.1002/(SICI)1099-0801(199906) 13:4<309::AID-BMC881>3.0.CO;2-J. PMID:10416066.

Lane, S.C., Areta, J.L., Bird, S.R., Coffey, V.G., Burke, L.M., Desbrow, B., et al. 2013a. Caffeine ingestion and cycling power output in a low or normal muscle glycogen state. Med. Sci. Sports Exerc. 45(8): 1577-1584. doi:10.1249/MSS. 0b013e31828af183. PMID:23439421.

Lane, S.C., Bird, S.R., Burke, L.M., and Hawley, J.A. 2013b. Effect of a carbohydrate mouth rinse on simulated cycling time-trial performance commenced in a fed or fasted state. Appl. Physiol. Nutr. Metab. 38(2): 134-139. doi:10.1139/ apnm-2012-0300. PMID:23438223.

Lansley, K.E., Winyard, P.G., Bailey, S.J., Vanhatalo, A., Wilkerson, D.P., Blackwell, J.R., et al. 2011a. Acute dietary nitrate supplementation improves cycling time trial performance. Med. Sci. Sports Exerc. 43(6): 1125-1131. doi: 10.1249/MSS.0b013e31821597b4. PMID:21471821.

Lansley, K.E., Winyard, P.G., Fulford, J., Vanhatalo, A., Bailey, S.J., Blackwell, J.R., et al. 2011b. Dietary nitrate supplementation reduces the O2 cost of walking and running: a placebo-controlled study. J. Appl. Physiol. 110(3): 591-600. doi:10.1152/japplphysiol.01070.2010. PMID:21071588.

Larsen, F.J., Schiffer, T.A., Borniquel, S., Sahlin, K., Ekblom, B., Lundberg, J.O., et al. 2011. Dietary inorganic nitrate improves mitochondrial efficiency in humans. Cell Metab. 13(2): 149-159. doi:10.1016/j.cmet.2011.01.004. PMID: 21284982.

Maher, A.R., Milsom, A.B., Gunaruwan, P., Abozguia, K., Ahmed, I., Weaver, R.A., et al. 2008. Hypoxic modulation of exogenous nitrite-induced vasodilation in humans. Circulation, 117(5): 670-677. doi:10.1161/CIRCULATIONAHA.107.719591. PMID:18212289.
McNaughton, L.R., Lovell, R.J., Siegler, J., Midgley, A.W., Moore, L., and Bentley, D.J. 2008. The effects of caffeine ingestion on time trial cycling performance. Int. J. Sports Physiol. Perform. 3(2): 157-163. PMID:19208924.

Muggeridge, D.J., Howe, C.C., Spendiff, O., Pedlar, C., James, P.E., and Easton, C. 2013. The Effects of a Single Dose of Concentrated Beetroot Juice on Performance in Trained Flatwater Kayakers. Int. J. Sport Nutr. Exerc. Metab. 23(5): 498-506. PMID:23580456.

Paton, C.D., and Hopkins, W.G. 2006. Variation in performance of elite cyclists from race to race. Eur. J. Sport Sci. 6(1): 25-31. doi:10.1080/17461390500422796.

Pottier, A., Bouckaert, J., Gilis, W., Roels, T., and Derave, W. 2010. Mouth rinse but not ingestion of a carbohydrate solution improves 1-h cycle time trial performance. Scand. J. Med. Sci. Sports, 20(1): 105-111. doi:10.1111/j.1600-0838. 2008.00868.x. PMID:19000099.

Ross, M.L., Garvican, L.A., Jeacocke, N.A., Laursen, P.B., Abbiss, C.R., Martin, D.T., et al. 2011. Novel precooling strategy enhances time trial cycling in the heat. Med. Sci. Sports Exerc. 43(1): 123-133. doi:10.1249/MSS.0b013e3181e93210. PMID:20508537.

Ross, M.L., Jeacocke, N.A., Laursen, P.B., Martin, D.T., Abbiss, C.R., and Burke, L.M. 2012. Effects of lowering body temperature via hyperhydration, with and without glycerol ingestion and practical precooling on cycling time trial performance in hot and humid conditions. J. Int. Soc. Sports Nutr. 9(1): 55. doi:10.1186/1550-2783-9-55. PMID:23245800.

Russell, G., Gore, C.J., Ashenden, M.J., Parisotto, R., and Hahn, A.G. 2002. Effects of prolonged low doses of recombinant human erythropoietin during submaximal and maximal exercise. Eur. J. Appl. Physiol. 86(5): 442-449. doi:10. 1007/s00421-001-0560-6. PMID:11882931.

Ryan, E.J., Kim, C.H., Fickes, E.J., Williamson, M., Muller, M.D., Barkley, J.E., et al. 2013. Caffeine gum and cycling performance: a timing study. J. Strength Cond. Res. 27(1): 259-264. doi:10.1519/JSC.0b013e3182541d03. PMID:22476164.

Tarnopolsky, M.A. 2008. Effect of caffeine on the neuromuscular system potential as an ergogenic aid. Appl. Physiol. Nutr. Metab. 33(6): 1284-1289. doi:10.1139/H08-121. PMID:19088790.

Vanhatalo, A., Fulford, J., Bailey, S.J., Blackwell, J.R., Winyard, P.G., and Jones, A.M. 2011. Dietary nitrate reduces muscle metabolic perturbation and improves exercise tolerance in hypoxia. J. Physiol. 589(22): 5517-5528. doi: 10.1113/jphysiol.2011.216341. PMID:21911616.

Wilkerson, D.P., Hayward, G.M., Bailey, S.J., Vanhatalo, A., Blackwell, J.R., and Jones, A.M. 2012. Influence of acute dietary nitrate supplementation on 50 mile time trial performance in well-trained cyclists. Eur. J. Appl. Physiol. 112(12): 4127-4134. doi:10.1007/s00421-012-2397-6. PMID:22526247.

Wylie, L.J., Kelly, J., Bailey, S.J., Blackwell, J.R., Skiba, P.F., Winyard, P.G., et al. 2013. Beetroot juice and exercise: pharmacodynamic and dose-response relationships. J. Appl. Physiol. 115(3): 325-336. doi:10.1152/japplphysiol.00372. 2013. PMID:23640589. 